NASA Technical Memorandum 103743

\title{
Ceramic Composites for Rocket Engine Turbines
}

Thomas P. Herbell and Andrew J. Eckel

Lewis Research Center

Cleveland, Ohio

Prepared for the

1991 Aerospace Atlantic Meeting

sponsored by the Society of Automotive Engineers, Inc.

Dayton, Ohio, April 23-27, 1991 


\title{
CERAMIC COMPOSITES FOR ROCKET ENGINE TURBINES
}

\author{
Thomas P. Herbell and Andrew J. Eckel \\ National Aeronautics and Space Administration \\ NASA Lewis Research Center \\ Cleveland, Ohio 44130
}

\section{ABSTRACT}

Use of ceramic materials in the hot section of the fuel turbopump of advanced reusable rocket engines promises increased performance and payload capability, improved component life and economics, and greater design flexibility. Severe thermal transients present during operation of the Space Shuttle Main Engine (SSME) push metallic components to the limit of their capabilities. Future engine requirements may be even more severe. In Phase I of this two Phase program, performance benefits have been quantified and continuous fiber reinforced ceramic matrix composite (FRCMC) components have demonstrated a potential to survive the hostile environment of an advanced rocket engine turbopump.

\section{INTRODUCTION}

Reusable rocket engines for future missions of earth-to-orbit and beyond must operate longer, withstand more duty cycles, and be more efficient than present generation engines. Today the most advanced reusable rocket engine of this type is the Space Shuttle Main Engine (SSME). Metal turbopump blades, stator vanes and other hot gas flow path components of this hydrogen/oxygen burning engine have limited durability. For improved efficiency, future Advanced Launch Systems (ALS) such as the Space Transport Booster Engine (STBE) and Space Transport Main Engine (STME) will require materials with greater temperature capability.

Materials with potential to significantly outperform the currently used superalloys include ceramics, synthetic alloys such as intermetallics, and carbon/carbon. These materials have a lower density and can operate at higher temperatures than superalloys (Fig. 1). of the candidate materials, ceramics exhibit better potential for overall tolerance to the aggressive rocket engine environment. The load carrying capability of monolithic ceramics is,

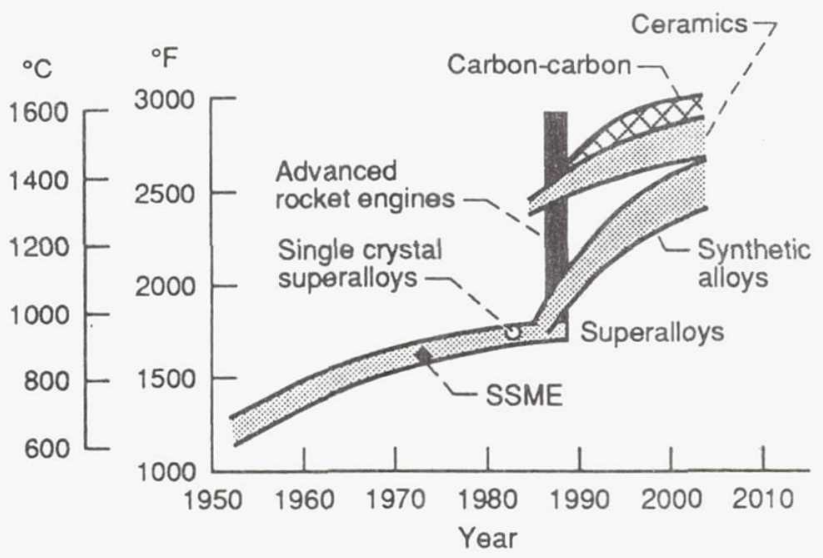

Figure 1.-Rocket engine turbine blade material needs and capabilities.

however, very sensitive to processing and service induced flaws. This leads to a low but finite probability of brittle (catastrophic) failure under thermal shock conditions. Catastrophic failure of this type can damage other engine components. Reinforcing ceramics with continuous ceramic fibers offers the potential for significant improvement in reliability and durability.

Fiber reinforced ceramic matrix composites (FRCMC) are a class of emerging materials that appear to possess property data that is encouraging. However, FRCMC systems have not been extensively characterized, particularly with respect to their use in a rocket engine turbine environment. Therefore, the work described in this paper was undertaken to further evaluate the feasibility of FRCMC for rocket engine use.

In 1988 a two phase program was initiated to implement the introduction of FRCMC into future generation earth-to-orbit (ETO) rocket engine turbine components. Phase I consisted of two 16 month contracts to identify the benefits and to assess the potential for the introduction of FRCMC turbine components. Contract work was performed at General Electric and Rocketdyne. 
A parallel effort at NASA Lewis was directed towards determining the ability of advanced FRCMC to withstand the severe thermal environment, particularly thermal shock, of a rocket engine turbine. Phase $I$ is now complete and $a$ Phase If contract to design, develop and test full scale prototype components is in place at Rocketdyne.

The objectives of this paper are to summarize the Phase I effort. The results described are from the Rocketdyne Phase I contract (1),* however, it should be noted that the General Electric researchers reached similar conclusions regarding the benefits of utilizing FRCMC (2). In both cases material systems were selected and prototype subcomponents were fabricated to demonstrate critical fabrication issues. A brief summary of the thermal shock evaluations conducted at NASA Lewis Research Center is also reported.

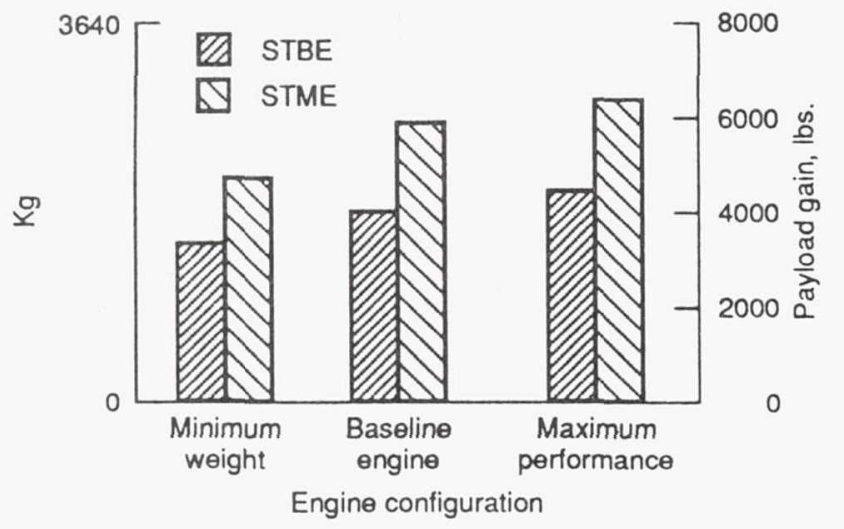

\section{RESULTS}

BENEFITS ANALYSIS - Introduction of FRCMC into the hot section of a rocket engine turbopump yields three types of benefits: increased performance and payload capability, improved component life and economics, and greater design flexibility.

Increased performance and payload capability - Cycle analysis studies indicate that increasing the turbine inlet temperature (TIT) of gas generator cycle engines, such as the STME, from a baseline condition of 870 to $1170{ }^{\circ} \mathrm{C}$ with FRCMC components results in improved performance and the potential for significant payload gains as shown in Fig. 2 . The benefit of increased TIT was quantified for ALS type engines including the STME and STBE. The results are summarized in Table I. Significant gains in specific impulse $\left(I_{s}\right)$ are possible for the baseline engine and for minimum weight and maximum performance configurations. Increased performance can decrease the cost of putting payloads into space by increasing payload for a specific configuration as shown in Fig. 2, by allowing reconfiguration of the vehicle to decrease its weight, or by permitting an engine configuration that reduces the nozzle exit area and engine weight.

Increasing TIT for staged combustion cycle engines such as the SSME result in only limited efficiency gains. The third type of engine system under consideration for ALS, the expander cycle, does not employ high inlet temperatures and was not considered.

Figure 2.-Increased turbine inlet temperature results in higher payloads (base payload $=7300 \mathrm{Kg}$ or $16000 \mathrm{lbs}$.).

TABLE I. - SPECIFIC IMPULSE INCREASES WITH INCREASED TURBINE INLET TEMPERATURE

\begin{tabular}{|c|c|c|}
\hline \multicolumn{3}{|c|}{ Vacuum performance increase for $1170^{\circ} \mathrm{C}\left(2600^{\circ} \mathrm{R}\right)$ operating temperature } \\
\hline Engine configuration & $\mathrm{LOX} / \mathrm{CH}_{4} \mathrm{STBE}$ & $\mathrm{LOX} / \mathrm{H}_{2}$ STME \\
\hline $\begin{array}{l}\text { Maximum performance engine } I_{s} \text { gain, sec } \\
\text { Baseline engine } I_{s} \text { gain, sec } \\
\text { Minimum weight engine } I_{s} \text { gain, sec }\end{array}$ & $\begin{array}{l}8.3 \\
7.5 \\
6.2\end{array}$ & $\begin{array}{l}5 \cdot 4 \\
4 \cdot 3 \\
3.2\end{array}$ \\
\hline \multicolumn{3}{|c|}{ Sea level performance increases for $1170^{\circ} \mathrm{C}\left(2600^{\circ} \mathrm{R}\right)$ operating } \\
\hline $\begin{array}{l}\text { Maximum performance engine } I_{\text {, gain, sec }} \\
\text { Baseline engine } I_{s} \text { gain, sec } \\
\text { Minimum weight engine I, gain, sec }\end{array}$ & $\begin{array}{r}13.1 \\
8.7 \\
6.3\end{array}$ & $\begin{array}{r}10.2 \\
4.3 \\
3.2\end{array}$ \\
\hline
\end{tabular}

"Numbers in parenthesis designate references at end of paper. 
Improved component 1 ife and economics - In 1983 chandler (3) projected a cost savings of up to $\$ 230 \mathrm{M}$ in 1983 dollars for replacing metal turbopump blades in the SSME fuel turbopump with ceramics. This estimate was based on 500 flights. A significant reliability improvement also results from the increased temperature capability of FRCMC. Greater temperature margin allows for temperature overshoot with reduced component damage relative to superalloys as shown in Fig. 3. Using the current design for

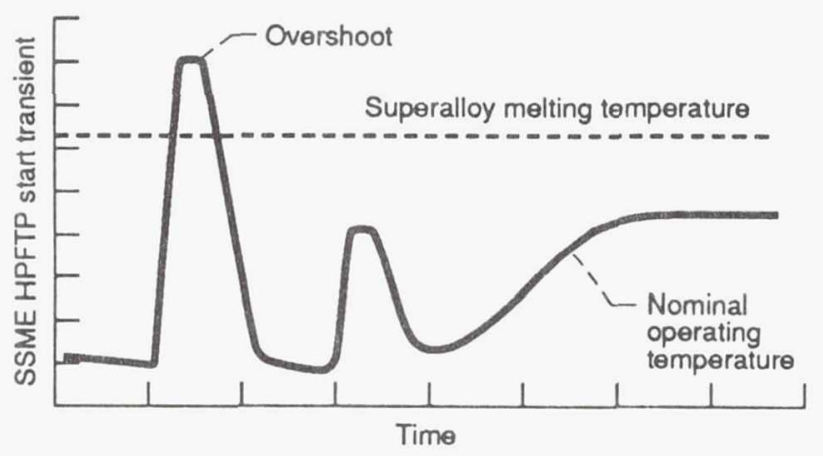

Figure 3.- Higher ceramic use temperature relative to superalloys permits greater overshoot with reduced component damage.

the SSME high pressure fuel turbopump, a direct substitution of FRCMC components would yield more than a $350^{\circ} \mathrm{C}$ increase in design temperature margin and a 20 to 35 percent reduction in turbine rotor mass. A reduction in rotor mass means a lower bearing load and possibly greater bearing life. Other benefits include the potential for increased bearing life due to improved balance. Life related properties data for FRCMC are currently insufficient to quantify these benefits.

Increased design flexibility - Lower rotating mass leads to reduced residual imbalance requirements for the rotating components, and also permits greater overhung distances in the turbines. Therefore, bearing shaft and disk requirements are relaxed and the airfoil envelope can be expanded to configurations closer to opt imum.

\section{SELECTION OF ENGINE COMPONENT/MATERIAL}

of the benefits derived from using FRCMC, performance is the easiest to directly quantify. For a rocket engine turbine (1ike most heat engines) higher operating temperature means improved performance. The maximum desirable temperature, however, is often dictated by restrictions imposed by the engine system. With these restrictions in mind an operating tempera-

**A discussion of the reasons for selecting this particular temperature are beyond the scope of this paper. ture of $1170{ }^{\circ} \mathrm{C}$ was selected.** Both stationary (nozzle) and rotating (rotor) components were considered. Table II summarizes the matrix of engine types, propellant systems, and materials evaluated. The greatest gains were found to be for gas generator cycle engines. As noted in Table I, the LOX/CH 4 propelled STBE showed greater incremental gain in performance than the $\mathrm{LOX} / \mathrm{H}_{2}$ propelled STME. However, LOX $/ \mathrm{H}_{2}$ retained higher total $I_{\text {and }}$ was selected for more detailed studies. There are also indications that $\mathrm{LOX} / \mathrm{H}_{2}$ probably will be the propellant system of choice for ALS.

A large number of FRCMC materials were screened for potential consideration. Table III lists these materials and the screening criteria used and Table IV shows the candidate systems selected. Selection criteria included known or predicted properties, the ability to tolerate rocket engine thermal transients, and durability in high temperature hydrogen rich steam. Based on projected rotor operating stresses the final material selected was C/SiC. This material exhibits the necessary combination of mechanical properties, fabrication and test experience at the component level and an acceptable environmental resistance for an early component demonstration. of the alternate materials, SiC/SiC has better environmental resistance but lacks the load carrying capability at operating temperatures. Carbon/carbon (C/C) requires a coating system (as yet not successfully developed) for use in the engine environment and $\mathrm{SiC} / \mathrm{Si}_{3} \mathrm{~N}_{4}$ is too immature for near term consideration.

Based on development and demonstration status, two-dimensional fiber architectures were selected for the fabrication of sub-components. Alternate procedures such as polar weaving show promise, but are as yet too immature for near term component demonstration. Much work is underway with the polar weaving approach and it is certainly possible that it may be applicable to full scale component demonstration in the future.

Like fiber lay-up, a number of alternate procedures for matrix development were also considered. Chemical vapor infiltration (CVI) emerged as the process of choice based on demonstrated processing capabilities for near net shape components with the desired combination of high toughness and resistance to catastrophic failure.

\section{LIMITATIONS OF FRCMC}

The use of FRCMC is hampered by a lack of detailed design analysis capability and by fabrication restraints.

Design limitations - The issue of designing components to be made from FRCMC is extremely important, particularly for complicated shapes such as rotors and nozzles. Statistical design methodology is just now being formulated. Also the required extensive material property database does not exist. Ultimate mechanical properties and thermal properties are available for 
TABLE II. - MATERIALS SELECTION MATRIX FOR ROTATING (ROTOR) AND NONROTATING (NOZZLE) COMPONENTS

\begin{tabular}{|l|c|c|c|}
\hline \multicolumn{1}{|c|}{ Engine cycle } & $\begin{array}{c}\text { Propellant } \\
\text { combination }\end{array}$ & $\begin{array}{c}\text { Specific } \\
\text { engine }\end{array}$ & $\begin{array}{c}\text { Fiber/matrix } \\
\text { system }\end{array}$ \\
\hline Gas generator & $\underline{L O X / H_{2}}$ & STME & C/SiC \\
Gas generator & LOX/CH & STBE & \\
Staged combustion & $\mathrm{LOC} / \mathrm{H}_{2}$ & SSME & \\
Staged combustion & LOX/CH & SSME & \\
& $\cdots$ & & \\
\hline
\end{tabular}

ITALICS with underlining indicates candidate selections. - C/SiC, SiC/SiC, SiC/Si $\mathbf{n}_{4}, \mathrm{C} / \mathrm{C}$ considered.

-.. Benefits of $\mathrm{LOX} / \mathrm{CH}_{4}$ evaluated but $\mathrm{CH}_{4}$ not actually used for SSME.

TABLE III. - SUMMARY OF FRCMC MATERIAL SYSTEMS AND SELECTION CRITERIA

\begin{tabular}{|l|l|}
\hline Fiber/matrix systems evaluated & Screening criteria used \\
\hline SiC/lithium-alumino-silicate & Maximum operating temperature \\
SiC/magesium-alumino-silicate & \\
SiC/calcium-alumino-silicate & Thermal shock resistance \\
SiC/black glass & \\
SiC/borosilicate & Environmental resistance \\
SiC/silica & Ultimate tensile strength \\
C/lithium-alumnio-silicate & \\
C/borosilicate & Fracture toughness \\
C/alumina & Fabricability \\
SiC/silicon nitride & SiC/SiC \\
C/SiC & Maturity \\
C/C & \\
\hline
\end{tabular}

TABLE IV. - CANDIDATE MATERIAL SYSTEMS

\begin{tabular}{|c|c|c|c|c|c|}
\hline Fiber/Matrix & $\begin{array}{l}\text { Temp- } \\
\text { erature }\end{array}$ & $\begin{array}{c}\text { Thermal } \\
\text { shock }\end{array}$ & $\begin{array}{l}\text { Environ- } \\
\text { mental } \\
\text { resist- } \\
\text { ance }\end{array}$ & $\begin{array}{l}\text { Mechanical } \\
\text { properties }\end{array}$ & Maturity \\
\hline $\begin{array}{l}\text { SiC/silicon nitride } \\
\mathrm{SiC} / \mathrm{SiC} \\
\mathrm{C} / \mathrm{SiC} \\
\mathrm{C} / \mathrm{C}\end{array}$ & 1 & 1 & $\begin{array}{l}1 \\
1 \\
2 \\
2 .\end{array}$ & $\begin{array}{c}4 \\
2 \\
1 \\
1-2\end{array}$ & $\begin{array}{l}3 \\
2 \\
1 \\
1\end{array}$ \\
\hline
\end{tabular}

1-Acceptable 2-Marginal 3-Not acceptable 4-Not known.

- - Coating desired/needed. 
the C/SiC architectures being considered. There is, however, only very limited time dependent property and environmental stability data available. A point of particular concern here is the interactive effects of cyclic loading with environmental effects at operating temperatures.

At present, structural analysis is limited to the micromechanical approach. The existing design codes are only capable of using anisotropic properties. While some nonlinear material characteristics can be considered in the analysis, detailed data are very limited. It is obvious that a considerable design tool development effort is required in this area. At present we must rely heavily on experience-based design approaches.
Fabrication limitations - Table V lists a number of the fabrication restraints imposed by the use of FRCMC manufactured by CVI of fiber preforms. Machining is a particular concern for $\mathrm{C} / \mathrm{SiC}$. Exposure of the fibers to the turbine environment is undesirable, thus machining must be done prior to the final coating which is done by chemical vapor deposition (CVD). Only very minor touch-up machining is permissible after the final CVD. The CVI process is accomplished by a series of infiltrations with alternating machining operations. This approach has a pronounced effect on balancing of rotating components. Shape forming limitations and the presence of residual porosity currently prevent the use of FRCMC for fabrication of pressure tight manifolds and housings.

TABLE V. - FRCMC FABRICATION LIMITATIONS

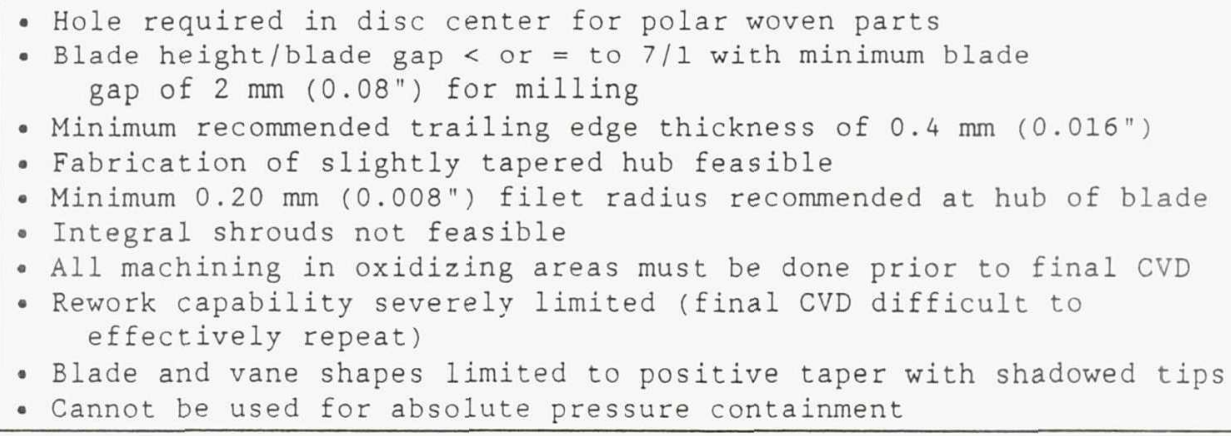

\section{PROTOTYPE SUBCOMPONENT FABRICATION}

The design limitations and fabrication restraints were factored into the development of turbine blade elements fabricated during the program. Subcomponents consisting of blade pairs attached to a simple base were produced. The blade pairs were utilized to demonstrate the current capability to machine between blades as required for a bladed disk or blisk. An actual blade pair, shown in Fig. 4, conforms to the fabrication limits indicated in Table $\mathrm{V}$. Nondestructive evaluation (NDE) of the blade pairs by computer assisted tomography (CAT) indicate that no internal delaminations are present. Fiber alignment within each of the three blade pairs fabricated was within $3^{\circ}$ of nominal, and part-to-part reproducibility showed very little process deviation. Surface finish was good, but characteristic surface-connected porosity was observed. Leading and trailing edges were intact with no chips or discontinuities due to machining. Comparison of the subcomponent features to design specifications confirms the feasibility of full-scale component fabrication.

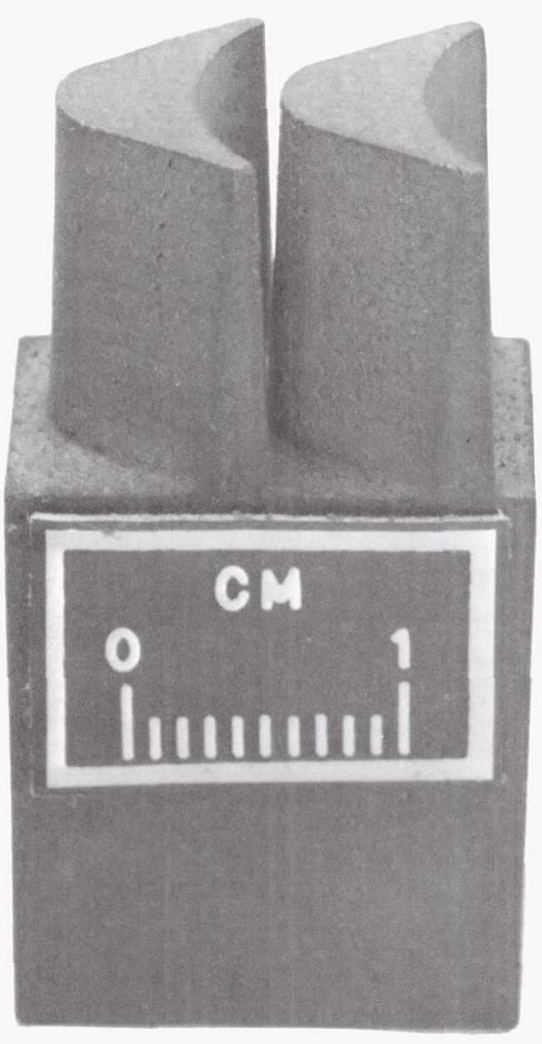

C-90-04079

Figure 4.-FRCMC turbine blade pair prepared by chemical vapor infiltration. 
THERMAL SHOCK TESTING OF FRCMC TEST BARS AND COMPONENTS

The parallel in-house evaluation of the environmental durability of FRCMC involved the use of a small hydrogen/oxygen rocket engine test rig to generate high heating rate thermal shock compatibility data. The rig is capable of controlled thermal shock temperatures $(\Delta T)$ of from 1000 to $2500{ }^{\circ} \mathrm{C} / \mathrm{sec}$. Initial tests with commercial $\mathrm{SiC}$ and $\mathrm{Si}_{3} \mathrm{~N}_{4}$ confirmed the suspicion that ceramics in monolithic form are not acceptable for use in high heating rate applications. FRCMC specimens including $\mathrm{SiC} / \mathrm{SiC}$ and $\mathrm{SiC} / \mathrm{Si}_{3} \mathrm{~N}_{4}$ demonstrated a capability to survive the severe thermal shock of a rocket engine. The thermal shock results for various test bar materials are shown in Fig. 5. Based on the success of FRCMC in test bar form, an individual blade from the blade pairs described in the previous section was tested in the rocket engine test rig.

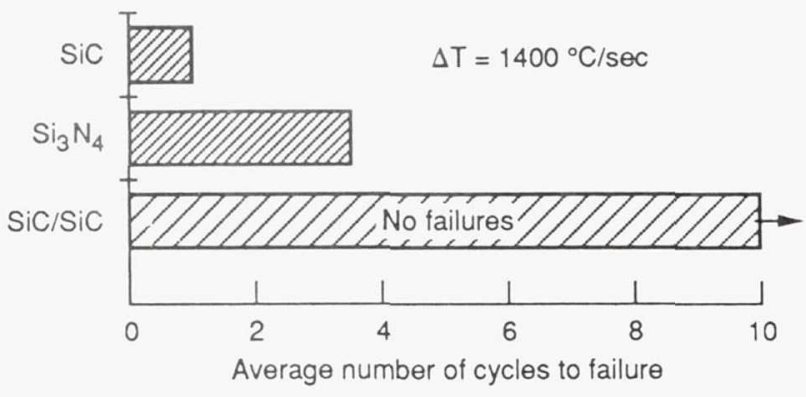

Figure 5.-FRCMC's resist thermal shock damage.

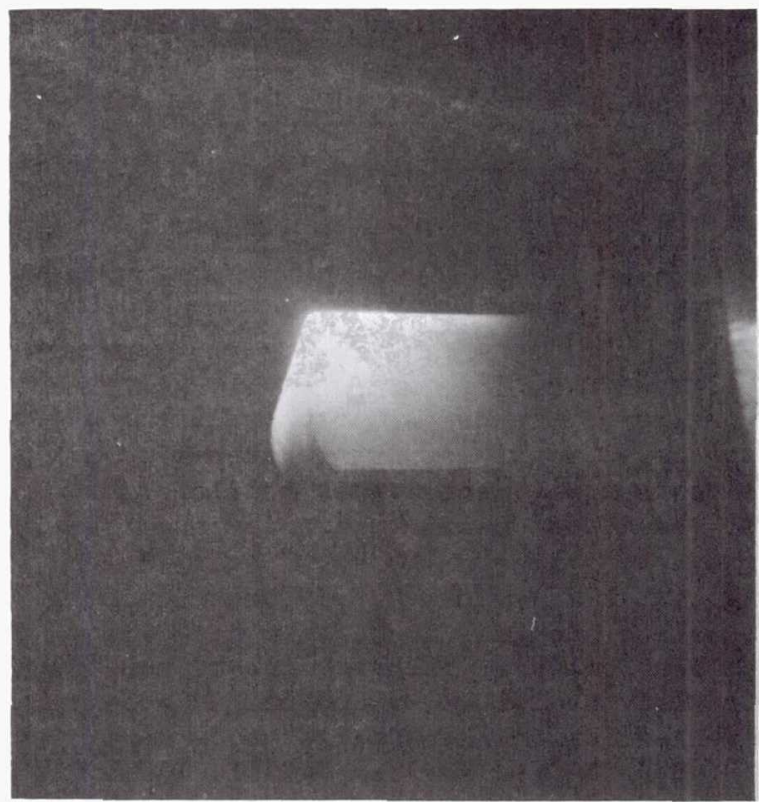

Figure 6.-FRCMC turbine blade during rocket engine rig test.
Figure 6 shows the specimen during test. The blade survived 50 thermal shock cycles of ambient to $1800{ }^{\circ} \mathrm{C}$ in $1 \mathrm{sec}$. Some leading edge erosion was noted, but only after 20 cycles. The imposed test condition is much more severe than anticipated in use and demonstrates the ability of a FRCMC component to survive the operating conditions of a rocket engine turbopump.

\section{SUMMARY}

Fiber-reinforced ceramic matrix composites (FRCMC) possess many of the properties projected to be required for advanced earth-to-orbit (ETO) rocket engine turbines, including low density, environmental stability, high use temperature, and improved toughness and reliability.

Use of FRCMC offers significant potential benefits including increased performance and payload capability, improved component life and economics, and greater design flexibility.

Performance benefits derived from increasing the TIT from 870 to $1170{ }^{\circ} \mathrm{C}$ are easiest to quantify. Cycle studies indicate a 3 to $10 \mathrm{~s}$ gain in specific impulse $\left(\mathrm{I}_{\mathbf{s}}\right)$ for $\mathrm{LOX} / \mathrm{H}_{2}$ in the STME with an associated payload gain of $2700 \mathrm{~kg}$ (6000 lb) per engine. For the STBE and $\mathrm{LOX} / \mathrm{CH}_{4}$ the $\mathrm{I}_{\mathbf{s}}$ gain is 6 to $13 \mathrm{~s}$ and the associated payload gain is $1800 \mathrm{~kg}$ (4000 lb) per engine.

For near term use, FRCMC feasibility can be demonstrated with two-dimensional, C/SiC produced by CVI of woven fiber lay-ups for highly stressed parts. Lower stressed components can make use of SiC/SiC in the hydrogen rich steam environment of a gas generator cycle engine.

FRCMC in test bar geometry and in actual turbine blade shapes have demonstrated the ability to survive the severe thermal shock environment of a rocket engine turbopump.

\section{CONCLUSIONS}

FRCMC are an emerging class of materials. Their status and fabricability into turbine components has been demonstrated. Thermal shock tests that approximate a rocket engine turbopump environment have produced encouraging results both for test bars and for prototype subcomponents. Further work is required to verify their capabilities for use in a full-scale rocket engine turbopump.

\section{FUTURE WORK}

A Phase II contract to design, fabricate, and test full scale rocket engine turbopump components in a turbopump environment is in place at Rocketdyne. Studies at NASA Lewis will evaluate the environmental durability of new FRCMC materials and component shapes as they become available. 


\section{REFERENCES}

1. J.W. Brockmeyer, and G.D. Schnittgrund, "Fiber-Reinforced Ceramic Composites for Earth-to-Orbit Rocket Engine Turbines," Rocketdyne Division, Rockwell International Corp., NASA Lewis Contract NAS3-25468, Phase I-Final Report, NASA CR-185264, July, 1990 .

2. G.D. Holloway, R. Eskridge, R. Singh, and S. Ward, "Fiber-Reinforced Ceramic Composites for Earth-to-Orbit Rocket Engine Turbines," GE Aircraft Engines, NASA Lewis Contract NAS3-25467, Phase I-Final Report, NASA CR-185290, July, 1990.

3. W.T. Chandler, "Materials for Advanced Rocket Engine Turbopump Turbine Blades," Rockwell International Corp., NASA Lewis Contract NAS3-23536, Final Report NASA CR-174729, November, 1983. 


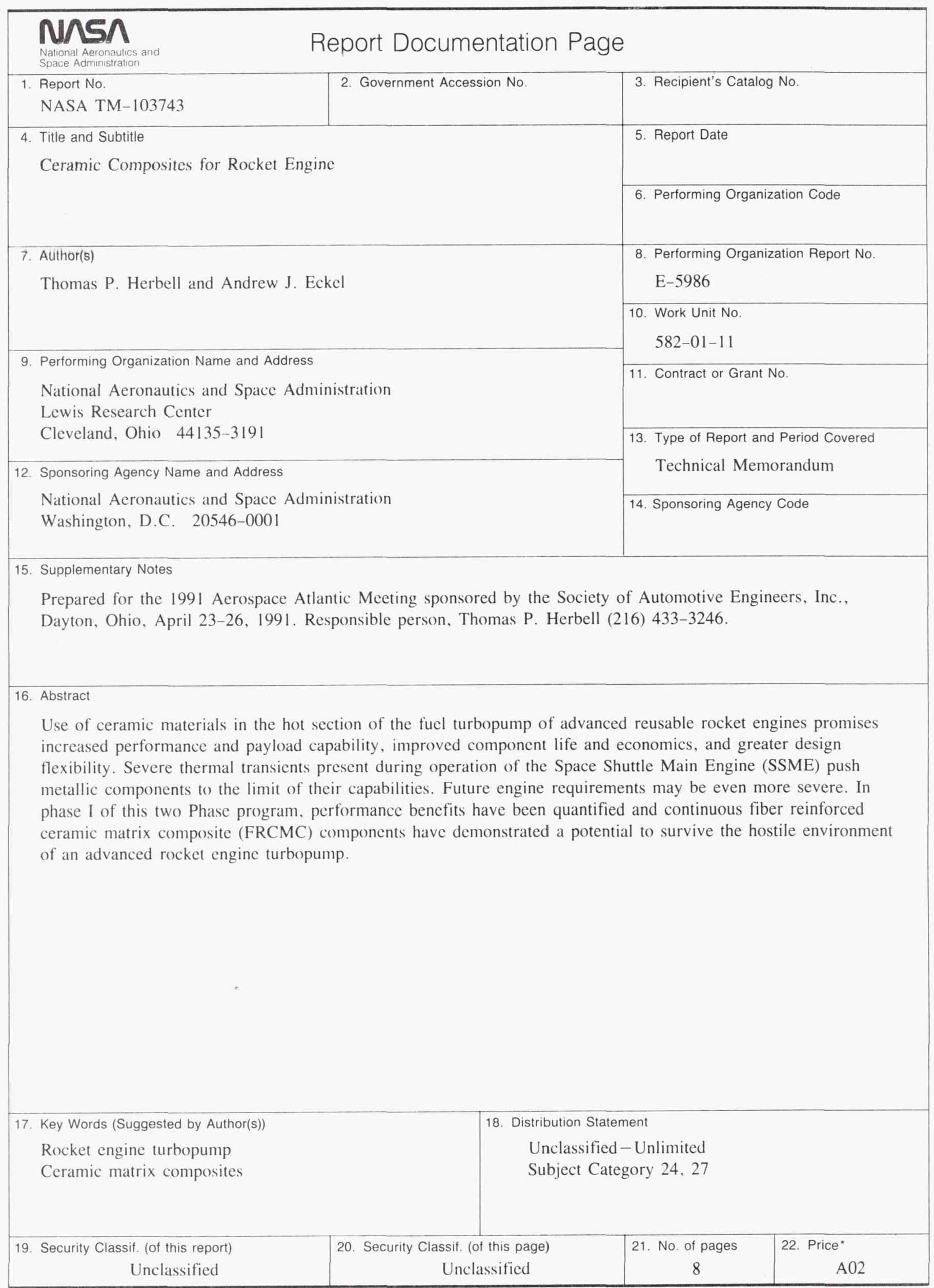

